

\title{
VERTICAL POLOIDAL ASYMMETRIES OF LOW-Z ELEMENT RADIATION IN THE PDX TOKAMAK
}

\author{
K. Brau," s. Suckewer \\ Plasma Pbysics Laboratory, Princelon Unirersity, \\ Princeton, New Jerney 08544
}

and

S. K. Wong

GA Technologies, San Diego, Galifornia

\begin{abstract}
Vertical poloidal asymmetries of bydrogen isotopes and low-Z impurity radiation in the PDX Lokamak may be caused by poloidslly asymmetric sources of these e!ements at gas inlet valves, limiters or vacuum vessel walls, asymmetric magnetic field geometry in the region beyond the plasma boundary, or by ion curvature drifts. Low ionization states of carbon (C II- C IV) are more easily influenced by edge conditions than is $\mathrm{C} V$. Vertical poloidal asymmetries of $\mathrm{C}$ $V$ are correlated with the direction of the toroidal field. The magnitude of the asymmetry agrees with the predictions of a quasifluid neoclassical model. Experimental data and numerical simulations are presented to investigate different models of impurity polcidal asymmetries.
\end{abstract}

\footnotetext{
* Current address: Anociation Euratom-CEA our la fusion, Deparkement de recherchen sur la Tusion controlee, Cr utre d'etudes nuclesiren, Fontenay aux Rones, France
} 


\section{INTRODUCTION}

Observations of pronounced vertical asymmetries in hydrogen isotope and impurity line emission from tokamak plasmas in recent years have prompted a reconsideratica of impurity transport processes near the plasma boundary. To the extent that low-Z element behavior in axisymmetric, large aspect ratio toroidal confinement devices can be described by a set of fluid or kinetic equations, it is generally assumed at low order in an expansion parameter that the impurity density is distributed symmetrically on flux surfaces. This result, common to both fluid and kinetic theories of plasma transport, is primarily due to the anticipated rapid parallel transport along feld lines. The theory breaks down if strongly poloidally asymmetric sources of impurities are present of if the symmetry of magnetic flux surfaces bas been destroyed. Either of these two situations can occur in the region of plasma beyond the limiter radius where hydrogen and the lowest ionization - Lates of an impurity ion reside.

These arguments are less valid within the main plasma volume. Although some fraction of the poloidsl variation of the lower ionization states propagates inward $b$ the combination of collisional ionizat" in and radial transport, the rapid parallel motion along field lines tends quickly to establish poloidal symmetry on a flux surface. Therefore any mechanism which is invoked to explain vertical asymmetries of a relatively highly ionized impurity must acconnt for this rapid parallel transport. Such is the case with the standard neoclassical theory of impurity transport. When the appropriate set of moment equations are solved to first order in the expansion parameter (the inverse aspect ratio 
$\epsilon=r(R)$, impurity concentrations are no longer poloidslly symmetric on a fux surface. These poloidal variations result from a cosibination of parallel friction between the main and impurity ions that is created by radial density and temperature gradients and the rertical ion drift due to the curvature of the toroidal magnetic feld. The coupling between the poloidal variations in the impurity density and the vertical drift produces the normally inward transport of impurities predicted by neoclassical ibcory.

According to the theory, the sign and magnitude of vertical asym. metries depends on the ion collisionality and on the vertical ion drift. A correlation betweed impurity poloidal asymmetries and these quantities was first reported for the case of VUV emission from $O V$ and $O V I$ in the Alcator $A$ tokamak. The magnitude of the asymmetries was found to scale approximately with a quantity equal to the distance which an impurity ion dritts radially during a poloidal excursion of one radian. It was claimed that vertical asymmetries were the result of outwardly drifting impurity ions striking the limiter on the side of the plasma in the direction of the vertical drift. In the case of higher ionization states closer to the center of the plasma which did not drift beyond the limiter radius, saymmetries were attributed to the coupling through collisional ionization to the asymmetries of the lower ionization st ates. Subsequentiy, the Alcator scaling of impurity asymmetries was reproduced by different authors using the standard neoclassical theory of trace impurity transport in a collisional plasma. These results were independent of interactions between the edge plasma and the limiter.

While it accounted successfully for the Alcator A data, the theory 
could not explain both the large magnitude and the time varying behavior of poloidal asy mmetries of low-Z impurity radiation observed in the PLT tokamak. ${ }^{2}$ This may have been partially a consequence of the higher impurity content of PLT ( $Z_{\text {eff }} \sim 3-4$ ) in which collisions among impurity ions dominate the ion dynamics. No correlation between the vertical drift parameter and the magnitude of low-Z impurity anymmetries was detected. Instead poloidal asymmetries were attributed to detsils of the gas input programming, positioaing of the aperture limiter, edge ion temperature, and plasma MHD stability. (Along similar lines, obser rations of enhanced impurity line emission near the limiter in Alcator A were attributed to the effect of local recycling. ${ }^{3}$ )

In this paper we hope to resolve some of the theoretical issues surrounding poloidal asymmetries of low-Z impurity emission in tokamaks by focusing on our experimental investigations of the poloidal distribution of carbon impurities in the PDX tokamak. A distinetion will be made between the behavior of the lower ionization states of carbon (C II, C III) normally located at or beyond the limiter radius in PDX circular discharges, and that of C V, which is generally peaked several centimeters inside the limiter radius. We shall attempt to account for the observed anymmetries of $\mathrm{G} \mathrm{V}$ on the basis of four different theoretical models. In addition to the mechanisms mentioned above, i.e., inward propagation of asymmetries bJ collisional ionization and neoclassical transport, two others will be discussed. The first involves charge exchange recombination between a poloidally asmmetric neutral hydrogen profile and impurity ions, and the second, a poloidally varying radial diffusion coefficient. Experimental evidence for each of the theories will be presented, along with the results of an 
appropriate two-dimensional numerical modeling of carbon transport.

The remainder of this paper is organized as follows. In Sec. I we describe the experimental apparatus for the messurement of radial impurity scans, and some aspects of the PDX tokamak that are relevant to the interpretation of the data. In Sec. II we survey the measurements of poloidal asy mmetries of carbon emission with respect to the different theoretical models. In Sec. 111 we discuss our results from the numerical modeling.

\section{EXPERIMENTAL DETECTION SYSTEM}

The PDX Fast Rotating Mirror (FARM) diagnostic, (Fig. 1) based on a prototype model used on PLT, ${ }^{2}$ performs continuous vertical (radial) or horizontal (toroidal) scans of the spectral line emission in the range $2000 \AA-$ $6500 \AA$. The spatial scanning element is a rectangular aluminized quartz prism which can be rotated $90^{\circ}$ in a direction orthogonal to its axis of rotation to select between vertically and horizontally scanning lines of sight. A set of two UV grade quarte lenses focuses plasma radiation onto the entrance slit of a 0.5 m air monochromator. For vertically scanning lines of sight, the angular region in which radiation is detected by the systern corresponds to a rectangular spot 2-cm wide by 0.4-em high at the nominal iocation of the magnetic axis of a PDX discharge. A shaft encoder mounted to the drive shaft of the rotating mirror allows the angular coordinate of the rotating mirror to be determined absolutely as a function of time. Due to slight variations in the mirror rotation speed (approximately $720 \mathrm{RPM}$ ) from scan to scan, and also to the magnetic axis during 
a discharge, the uncertainty in the radial location of maximum signal intensity is roughly $1-2 \mathrm{~cm}$. The signal was digitized using a 10 bit $A / D$ converter at a sampling rate of $25 \mathrm{kHz}$, and subsequently anslyzed with a PDP.10 compuler.

During most of the period in which the data presented below were obtained, the inner wall of the racuum vessel was shielded by a set of highly reflective, titanium-carbide-coated, graphite tiles that were designed to absorb incident neutral bearn power. To minimize reflections from the tiles in vertical scans of the plasma, a viewing dump $(80 \mathrm{~cm} \times 10 \mathrm{~cm})$ was mounted on the inner wall. It was found on the basis of toroidal scans of line emission that the dump reduced the signal intensity by as much as $\mathbf{1 0 \%}$ as a result of eliminating reflections. In the vertical and horizontal directions the sensitivity of the FARM system, excluding effects due to reflections from the vacuum vessel, was independent of the angular position of the scanning mirror.

In PDX discharges can be run in either a circular or diverted configuration. In this paper only data obtained during circular discharges are presented because of the difficulty in interpreting impurity emission in the region beyond the magnetic separatrix in diverted discharges. Circular discharges are normally confined using two movable carbon rail limiters located above and below the plasma. For a several month period only the upper limiter was employed. The FARM is located approximately $180^{\circ}$ toroidally around the vacuum vessel from the rail limiters. A second method of creating circular plasma configurations is to use the inner wall armor as a toroidally continuous "bumper" limiter. For the data presented in this paper $R_{\text {mej }}=125-154 \mathrm{~cm}$ and $a=30-44 \mathrm{~cm}$. 


\section{Data analysis}

The technique of Abel inversion is frequently used to convert line inlegrated intensities to local plasma emissivities. Usually the inversion assumes cylindrical symmetry or else some expansion in poloidal harmunics. We have deveioped a fast, relatively accurate method of invertirig asymmetric chordal profiles without recourse to Abel inversion which is weil-suited to analy zing large numbers of radial scans. The emissivity profile is assumed to have the following form:

$$
\left.I(r, \theta)=J_{0} \exp \left[-\left(\left(r-r_{0}\right) / \delta\right)^{2}\right](1+\eta \sin \theta)\right]
$$

where $r$, is the radius of maximum emissivity, $\delta$ the width at half maximum, and $\eta$ is defined as the asymmetry parameter. The corresponding chordal intensity profile is determined by integrating this function along fifty vertically scanning lines of sight. By analogy with the quantities $r_{e}, \eta$, and $\delta$, there are three parameters which characterize the chordal profile: the radial position of maximum intensity, the ratio of the maximum intensity above and below the midplane, and the width of the distribution. By numerically integrating $I(r, \theta)$ for a wide range of values of $r_{n}, \delta$, and $\eta_{1}$ a simple empirical relationship can be found which relates the two setu of parameters defining the emissivity and chordal profiles.

\section{EXPERIMENTAL OBSERVATIONS}

In the PDX tokamak low-Z impurity line emission arises from two regions in the discharge: the main plasma, defined here as the volume inside 
the limiter radius, and the limiter shadow, which refers to the region between the limiter radius and the vacuum vessel walls. In the latter region flux surfaces are not well-defined, and the poloidal distribution can be affected by recycling or local sources of impurities. Figure 2 is a schematic of the magnetic flux geometry of a standard PDX circular discharge. In the limiter shadow, defined as the region of plasma beyond the flux surfee bounded by the upper and lower limiters, the distance between the limiter radius and the walls of the vacuum vessel varies with poloidal angle. Furthermore, the length of the emitting region of an impurity located in the limiter shadow depends to a large extent on the electron temperature, typically $10-20 \mathrm{eV}$, and on other factors which are poorly known aud may vary with poloidal angle. Hence, small scale modulations in the chordal intensity profiles of the lowest ionization states of carbon and oxygen in PDX may reflect variations in the length of the emitting region, differences in the impurity source rates, recycling of impurities, end so on, rather than a variation in the impurity concentration on a flux surface. Figure 3 is an example of a chordal profile of $\mathrm{C}$ lll which exhibits this behavior. The irregular structure of the profile is repeated throughout the discharge and sometimes over many days of operation.

While the majority of chordal profiles of $\mathrm{C}$ III did not exhibit these small scale spatial variations, they were often characterized by large vertical asymmetries. In general, the position of maximum intensity was located 1-2 $\mathrm{cm}$ beyond the limiter radius. These asymmetries may be related to conditions at the edge of the plasma. In Fig. 4 chardal profiles of $\mathrm{C}$ III and C V have been plotted for a set of circular discharges with similar operat- 
ing parameters but for two different. major radial positions of the magnetic axis. Note that the radial profile of $\mathrm{C}$ III for the $R=152 \mathrm{~cm}$ discharge is extremeiy asymmetric in comparison to the standard $R=143 \mathrm{~cm}$ discharge. This may have been due to an error in the magnetic feedback positioning system which caused the large major radius discharge to impinge on the bottom half of the vacuum ressel. Becsuse only $C$ III is strongly asymmetric, this is a clear indication of a poloidslly asymmetric source of carbon at the edge. Line integrated radiated power profles measured by a vertically scanning bolometer array also showed a strong peaking of the radiation at the edge of the plasma below the midplane for the $R=152 \mathrm{~cm}$ discharge.

Secondly, we note that the smaller poloidal asymmetry of $\mathrm{C} \mathrm{V}$ is independent of the C III distribution. Poloidal asymmetries in the lower ionization states of carbon can in principle be transmitted to the higber ionization states by a combination of inward radial transpoit and collisional ionization. This in fact was among the explanations of the observation of poloidal asymmetries in the more highly ionized impurity species in Alcator $A^{1}$ and of subsequent measurements of toroidal asymmetries in the same tokamak. ${ }^{3}$ Asymmetries in the charge states near the plasma boundary that were directly affected by the vertical ion drift to the limiter constituted an asymmetric source function for the more highly stripped ious. The difficulty with this theory in explaining the PDX observations is that the parallel diffusion time of $G V$ is much shorter than the time required for a carbon ion to drift radially from the position of $\mathrm{C}$ 1II to $C \mathrm{~V}$. In PDX the parallel transport is sufficiently fast so that the asymmetry of C III has practically no influence on the poloidal distribution of $\mathrm{C} \mathrm{V}$. This topic 
is explored further in the numerical modeling section.

Figure 5 illustrates the effect of gas recycling on the poloidal distribution of impurities. The line integrated densities of two discharges with similar parameters are plotted as a function of time in the upper two figures; the lowcr graphs are radial scans (chordal profiles) of C Ill during the same period of time. In the right hand set of graphs the asymmetry of $\mathbf{C}$ IIl reversed direction at 620-650 msec into the discharge. Simultaneously, the electron density leveled off for approximstely 30 msec. We have determined that this flattening of the electron density was not caused by a change in gas fueling, but was probably a result of increased recycling of bydrogen and/or impurities at the plasma boundary. The reversal of the impurity asymmetry was observed in approximately twenty discharges for which the density flattening occurred, but never in discharges where the density decreased monotonically at the end of the discharge. In all of the discharges only the upper limiter was in use. It is therefore possible that the reversal of the C III asymmetry was due to jmpurity recjeling at the upper limiter, since the intensity of the C III emission increased in the upper half of the discharge during the flattening of the electron density. (For the value of $q$ at the plasma periphery the carbon plume emitted near the limiter would have traversed a poloidal angle of $40^{\circ}$, assuming purely parallel motion, as it reached the toroidal location of the FARM.)

Impurity poloidal asymmetries have alsc been attributed to charge exchange recombination of impurity ions with a poloidally asymmetric neutral bydrogen profile. ${ }^{4}$ According to this theory, the sign of the asymmetries of the neutral species is oppcsite that of the ions. In PDX we have obtained chordal 
profiles of $H_{\beta}, G M l$, and $G \mathrm{~V}$ emiasion under similar discharge conditions. Generally, the vertical anymuetry of the neutral component is the anme $2 x$ that of carbon ions, although there are exsmples in whith the poloidal aymmetry of $H^{0}$ changes sign during a diacharge, but the dintribulion of the innised specien remains constant. Beth of these results directly contradict the predictions of the theoretical model.

We have already noted the importance of plammaruface interactiona and vacuum vessel grometry in explaining the foloidal variation in the chordal prefiles of the lowest impurity ionisation staies. As was reed in Fis. 4, however, the vertinal asymmetry of a more highly ionized impurity auch as $\mathrm{CV}$ is unrelated to edge conditions. These exceptiont notwithetanding, in a majority of cases the sign of the vertical asymmetries of carbou and oxysen is the same and depends only on the direction of the toroidal wagnetic Beld. Figuse b represents a set of radiai scans of C III, G V, O Jll, and $\mathrm{OV}$ in a scries of aimilar ohmically heated hydrogen discharges with the following paramelers: $a=30 \mathrm{~cm}$, $\bar{\pi}_{e} \sim 2.7 \times 10^{18} \mathrm{~cm}^{-3}, \Xi_{T}=21.7 \mathrm{kG}$, and $I_{\mathrm{r}} \sim 200 \mathrm{kA}$. The direction of the asymmetries of carbon and oxygen is opposite the vertical jon drift in each case. The magnitude of the asymmetry is largest for the lower charge states of $\mathrm{C}$ III and $O \mathrm{Ill}$ and is a decreasing function of radius from $\mathrm{O}$ V to $\mathrm{C} \mathrm{V}$. It is unlikely that the impurity source functions aro the reason for the asymmetry, since the sources of carbon and oxygen may in general be different anit the diatributions of $\mathrm{C}$ III and $\mathrm{O}$ III are similar. These data also demongtrate that the vertical ion drift, if indeed $i$ is the mechanism producing the asymmetry, has the same influence on carbor and oxygen impurities. 
A correlation betmeen vertical poloidal impurity aymmetries and the direction of the toroidal field was first observed in the Alcator A tokamak.' The magnitude of the anymetry was found to scale with a quantity equal to the radial excursion of an impurity ion (due to the $\nabla B$ drift) during a poloidal transit of one radian. To explain the magnitude and direction of the impurity: poloidal asymmetries obwerved on $A_{1}$ cator $A_{1}$ and also to account for the change in asymmetries during a single discharge sometimes observed in PLT, ${ }^{2}$ Burrell snd Wong ${ }^{b}$ developed a neoclessical fluid model for amall poloidal impurily asymmetries. Impurity asymmetries arise as a result of the return flows of ions along lux surfaces induced by poloidal variations of density and temperature created by the ion vertical drift. The theory correclly predicted the scaling of the impurity asymmetry on Alcalor A. It was alse in principle capable of accounting for reversals in the sign of the asymmetry, a this depends on the relative magnitudes of the ion density and temperature gradients, which can change during a discharge.

Before embarking on a more quantitative discussion of these concepts, we illustrate the relationship between the vertical ion drift and impurity asymmetries in PDX. In Fig. 7 are shown two chordal profles of C IIl obtainad during "inner wall" operation, i.e., in vilich the graphite tiles on the inbosrd side of the vacuu, wel were used as a toroidally ccutinuous bumper limiter. The central emissivity maximum is caused by the desorption of carbon from the inner wall armor. Hence, the source of carbon is agmiatric about the horizontal midplane. Nevertheless, the sign of the vertical poloidal asymmetry of C III is in the same direction with respect to the vertical ion drift as observed in Alcator $\mathbf{A}$. 
Figure 8 illuntrates the effect of revereing the toroidal field on the poloidal asymmetry of $\mathrm{C}$ III and $\mathrm{C}$ V for a wet of otherwise nearly identical discharges. For each radial scan the sign of the anjmmetry is opposite the direction of the rertical ion drift.

To establish a quantitative relationabip between the magnitude of the impurity asymmetries in PDX and the prediction of the neoclassical tranaport model we have focused on $\mathrm{C} \mathrm{V}$ because it is relatively unaffected by conditions at the edge of the plasma. Thus it is possible to inolate the effects of the vertical ion drift from those of impurity recjcling, and so on. There are, however, a few points which must be addressed. First, althougb. PDX plasmas are re!itively clean $\left(Z_{\text {sff }}<2\right)$, colliaion between impurity ions, ignored in the theory, probably constitute an important part of the impurity dynamica. Second, the model of Burrell and Wong does not consider either atomic physics or anomalous radial transport, both of which determine the radial distribution of impurity species. Third, the model treats ions in the Ptirsch-Schlüter regime, while the bulk ions and to some extent $C \mathrm{~V}$ are in the plateau ragime. One of the authors of this paper (S. K. Wong) has reformulated the neoclassical fluid equations of impurity transport in which atomic physics and radial anomalous diffusion terms are included, and ions may be in either the plateau or fluid regimes. The major simplification of this theory is in the form of the collision operator. A derivation if these equations is given in the appendix. One can make an approxnate comparison between the magnitude and scaling of the observed asymmetries of $\mathrm{C} \mathrm{V}$ with the predictions of the quasifluid model by retaining three terms in the impurity transport equation (Eq. 11 of Appendix) to obtain 


$$
\eta_{q f}=\frac{2 \sqrt{\left.2 c R m_{i} q^{2} Z\right\}}}{e B_{T} T_{i}}\left[\frac{1}{L_{n}}+\left(1-\varepsilon-\frac{1}{Z_{l}}\right) \frac{1}{L_{T}}\right]-\frac{Z_{I} \sqrt{\pi} \epsilon p_{i}}{2 L_{T}} \frac{T_{c}}{T_{t}+T_{i}}
$$

where $Z_{t}$ is the charge of the impurity ion, $r_{i}$ the ion collision frequency, $\xi$ a constant equal to 1.5 and -0.75 in the plateau and banana regimes, respectively, $R$ the major radius, and the ion temperature $T_{i}$ is assumed to be equal for all the ion species. The asmmetry parameter $\eta_{y}$ is defined by the relation

$$
n_{I}(\theta, r)=n_{I}(r)\left(1+n_{I} f \sin \theta\right)
$$

Figure 9 is a plot of the experimental value of $\eta$ measured for roughly BO0 radial scans of $\mathrm{C} V$ in $\mathrm{PDX}$ rersus the quasifiuid model predictions. Information about both the ion temperaiure and density profiles was not available in the majority of the data; hence $T_{i}$ and $T_{i}$ were taken to be constant over the entire data set. The temperature of $\mathbf{C ~ V}$, in general, does not fluctuate by more than $\pm 10 \%$ in the circular onmically heated dischergen for which we have data $\left(T_{i} \sim 180-220 \mathrm{eV}\right)$. The density profile was measured by the TV Thomson Scattering diagno tic, or, if such data were not arailable a parabolic profile was fit to the measurements of the line integrated denuity. "he safety factor $q$ at the radius corresponding to the $\mathrm{C} \mathrm{V}$ shell was deiermined by interpolation from the value at the edge. If the diacharge parameters were nearly constant over the course of several radial scans, the data wern averaged. In the figure the volume of a box is linearly proportional to the number of acans.

In PDX at the radius of the C V shell the main plasma ions lie in the transition region between the plateau and collinionless regimes $\left(\nu_{*} \sim 1\right)$. We have therefore plotted the experimental data assuming each collisionality as a 
separate case. According to Fig. $g(a)$ if the plateau regime formula is used, the agreement with the theoretical prediction (dashed line) is very poor. However, in the banana regime (Fig. 9b) the agreement is excellent. To obtain a more accurate representution of the theoretical value of $\eta$ requires a correct solution for the quantity $\xi$, which lies somewhere between 1.5 and -0.75 in the bananaplateau transition regime.

The quasifuid model of poloidal wymmetries treats ion collisions using a simple Lorentz collision operator. In the platesu regime one must resort to a completely kinetic spproach in crder to treat ion-ion eacourters properly, which involves a reformulation of the problem in terms of the drift kinelic equation. An expression for the vertical impurity asymmetry in this kinetic theory has been obsiained by neglecting atomic phyaics and assuming trace impurities. Because the radial distribution of $\mathrm{C} V$ is well separated in space from adjacent ionization strtes, as a first approximation the atomic coupling due tu ionization and recombination ca: be ignored. In the limit where the mass of the impurity ion is mucb greater than the plasma ion we have

$$
\eta_{k}=-\frac{1}{2} \sqrt{\frac{m_{I}}{m_{i}}} \rho_{i q}\left[\frac{n_{i}^{\prime}}{n_{i}}+\left(\frac{3}{2}-\frac{Z_{I}}{2 \pi^{1 / 2}} \sqrt{\frac{m_{i}}{m_{I}}}\right) \frac{T_{i}^{\prime}}{T_{i}}\right]
$$

where the su'wacripts I and $i$ refer to impurities and protons, respectively, and $\rho_{i}$ is the proton Larmor radius in the toroidal field. Figure $10(b)$ is a plot of the asymmetry parameters of $\mathrm{CV}$ versus $\eta_{k}$. Although the magnitude of the asymmetry predicted by the kinetic model is within the range of observatious, the functional dependence is completely incorrect. Since the asymmetry of $\mathrm{C} \mathrm{V}$ scales with electron density (Fig. 10(a)), however, the lack of agreement between 
the kinetic model and experiment may be related to the fact that $\eta_{k}$ depends on the density gradient rather than the density itself.

\section{NCMERICAL MODELING}

We have developed a computer cede to solve an arbitrary set of coupled 2-D transport equations for the case of carbon impuaitics in PDX. The code is based on a finite element routine nupplied by IMSL, and an atomic physics package used in one-dimensional simulations of impurity transport. ${ }^{7}$ The general set of coupled equations to be solved are of the form

$$
\begin{gathered}
\frac{\partial n^{i}}{\partial t}+\frac{1}{r^{2}} \frac{\partial}{\partial \theta} D_{e} \frac{\partial n^{i}}{\partial \theta}+\frac{1}{r} \frac{\partial}{\partial r}+D_{r} \frac{\partial n^{i}}{\partial r}+ \\
f^{i}(r, \theta) \frac{\partial n^{i}}{\partial \theta}+g^{i}(r, \theta) \frac{\partial n^{i}}{\partial r}= \\
n_{e}\left[\alpha_{i+1} n^{i+1}+S_{i-1} n^{i-1}-\alpha_{i} n^{i}-S_{i} n^{i}\right]
\end{gathered}
$$

where $D_{,}$and $D_{r}$ are poloidal and radia! diffusion coefficients, $f^{i}$ and $g^{i}$ are arbitrary functions with units of velocity, and the $\alpha_{j}$ and $S_{j}$ are recombination and ionization rate coefficients, respectively. Because we are interested only in equilibrium solutions, the time derivative term is set tc sero. The density of one of the lowest ionization states $\left(\mathrm{C}^{0}\right.$ or $\mathrm{C}^{+1}$, depending on the problem) is specified at the boundary. Figure 11 is a plat of the density, temperature, and $q$ profiles for the PDX dischirgen modeled below. 
We firat investigated the effect of a nonasmmetric source of neutral carbon on the poloidal diatribution of the succensive ionisation states. In the simulation the radial transport of impurity ions is deacribed by anomalous diffusion and inward convection, and the parallel tranuport by collisional difusion. The latter assumption breaks down when the mean free path of an impurity ion is less than the parallel connection length $q R$. In PDX the transition from the collisional to the collisionless regime occurs a few centimeters within the radius of $\mathcal{U} V$. Hence the numerical unodel is appropriate for C II- C IV and marginally valid for C V. We have neglected the radial and parailel ion wotions due to magnetic field curvature and parallel friction. The 2-D diffusion equation for an impurity ion is given by

$$
-\frac{D_{H}}{R^{2} q^{2}} \frac{\partial^{2} n_{j}}{\partial \theta^{2}}-\frac{1}{r} \frac{\partial}{\partial r}+D_{A} \frac{\partial n_{i}}{\partial r}-\frac{1}{r} \frac{\partial r n_{j} U_{A}}{\partial r}=\Sigma_{j}
$$

where $D_{A}$ is an anomalous radial diffusion coefficient, $D_{\|}$'t he parallel diffusion coefficient, equal to $v_{i A}^{2} / \nu_{i}, \nu_{A}$ an anomalous conrective velocity, and $\Sigma_{i}$ represents ionization and recombination terms. $D_{A}$ and $v_{A}$ are determined empirically by comparison of the numerically calculated radisl emissivity profiles of $C$ III and C V with the experimental data. Because this procedure does not determine $D_{A}$ and $v_{A}$ uniquelv, we experimented with different combinations of the diffusion and convection coefficients. We found that the psioidal asymmetry is nearly indepenslent of the specific combination of diffusion and convection provider that they repraduce the correct radial dependence. In all of the numerical simulations, $D_{A}=10^{4} \mathrm{~cm}^{2} \mathrm{sec}^{-1}$ and $v_{A}=-2000(\mathrm{r} / \mathrm{a}) \mathrm{cm} / \mathrm{sec}$, where $a$ is the minor radius. The poloidal distribution of neutral carbon is assumed to vary as $1+0.25 \sin \theta$.

In Fig. 12 we have plotted the asymmetry parameters of C II-C VI as 
a function of radius. The four giaphs were obtained ansuming different valu's of iun collision frequency. It is clear that the asycumetry dioappears for C V unless $\nu_{i}$ was increased by a factor of ten from its experimental value. This lack of inficence of the source function on the $\mathrm{C} \mathrm{V}$ distribution is in agreement with experiment (see Fig. 4). These results further indicate that the poloidal asymmetry of $\mathrm{C} \mathrm{V}$ cannot be due to rertical ion drifts of the lower ionization states to the limiter.

We now wish to determine whether the lack of correlation betwean the poloidal asymmetry of neutral hydrogen and low- $Z$ impurity emission is consistent with theory. It is thus necessery to establish at what value of $n_{0} / n_{e}$ the charge exchange recombination rate of neutral hydrogen with carhon impurities becomes comparable to the parallel transport rate. Our numerical model is the same as used in the previous exampie, with the neutral hydrogen distribution given by

$$
n_{0}(r, \theta)=n_{0}(r)(1+.4 \sin \theta)
$$

The radial profile of the neutral density was determined by a one-dimensional simulation of neutral radial transport. ${ }^{6}$ As a result of recent theoretical calculations $^{8-12}$ and experimental measurements ${ }^{15}$ of charge exchange recombination rates for neutral hydrogen with the different ionization states of carbon, the uncertainties now $\mathrm{r}=5 \mathrm{~s}$ from $25 \%$ to a factor of two, which is less than the uncertainty in $n_{0}(r)$. For the purposes of simulation ye allowed $n_{0}(r)$ to be increased by factors of 2,5, and 10. At the boundary neutral carbon was assumed to be poloidally symmetric. 
Our results are shown in Fig. 13. There appears to be threshold neutral density above which the adymmetric neutral bydrogen profile has an effect on the carbon distribution, roughly $n_{0} / n_{a} \sim 5 \times 10^{-3}$. The charge state most affected by charge exchange recombination is $\mathrm{C} \mathrm{IV.} \mathrm{Noticc} \mathrm{that} \mathrm{C} \mathrm{V}$ and C VI are cylindrically syniminetric. Thus charge exchange recombination can be an important contribution to the vertical asymmetry of $C$ III and $C$ IV if the neutral hydrogen fraction at the edge exceeds $5 \times 10^{-3}$. To account for the observed poloidal asymmetry of $\mathrm{C} F$, the neutral fraction of bydrogen at the edge must be larger than $5 \times 10^{-2}$.

We did not model the full neoclassical quasifluid theory of poloidal asymmetries for the following reasons. Because the ion species of greatest inutrest, $C \mathrm{~V}$, lies in a region where the theory is least accurate $\left(\nu_{0} \sim 1\right)$, invoking the full numerical machinery is somewhat inappropriate since the equations themselves may not be correct for this transition collisionality. The estimates of $\eta$ obtained by retaining only three terms in the impurity transport equation are probably as accurate as the current theory permits. To determine whether the neglect of other quantities in the equation, such as atomic physics terms and anomalous radial diffusion, is justified, we modeled a simpler form of the impurity transport equation in which the poloidal variation of the electrostatic potential was ignored, and ions were assumed to be only in the collisional or plateau regimes. The values of $\eta$ for $C V$ derived from this numerical simulation agreed to within $10 \%$ of the value obtained by neglecting anomalous diffusion and atomic physics. (In order to bave the model produce large asymmetries to enable better comparison with the simplified approach, the temperature gradient 
scale leugth was assumed to be infinite, thereby neglecting the thermal force term.)

Finally, to investigate the effect of a poloidally varying anomalous radial diffusion coefficient on the carbon distribution in PDX, the following equation was modeled:

$$
-\frac{D_{\|}}{R^{2} q^{2}} \frac{\partial^{2} n_{k}}{\partial \theta^{2}}-\frac{1}{r} \frac{\partial}{\partial r} r D_{A}(\theta) \frac{\partial n_{k}}{\partial r}=S_{k}
$$

where $D_{A}(b)$ is taken to be of the form

$$
D_{A}(\theta)=(1+0.25 \cos \theta) D_{A}
$$

with $D_{A}=10^{4} \mathrm{~cm}^{2} \mathrm{sec}^{-1}$, and the neutral tarbon profile rassumed to be cylindrically symmetric. We found that the asymmetry parameter of every species was less than 0.02 unless $D_{A}$ and $\nu_{i}$ were each increased by a factor of five. Thus the parallel transport is simply too rapid to sustain poloidal asymmetries caused by an asymmetric diffusion coefficient.

\section{SUMMARY AND CONCLUSIONS}

In PDX there is a qualitative difference in the impurity behavior of ionization states in the Pfirsch-Schlüter regime (C II- C IV) and those in the plateau regime (C V) which relates to the proximity to the limiter. Impurity spesies located within the shadow of the limiter are more subject to edge processes such as recycling, and therefore vary substantially with plasma conditions, while the asymmetry of $\mathrm{C} \mathrm{V}$, which is located several centimeters inside the plasma 
boundary, varies less with edge conditions. Bath the experimental observations and the numerical nimulations indicate that the $\mathrm{C} \mathrm{V}$ asymmetry is not affected by that of the outer charge states. In general, the sign of the asymmelries of low ionisation states of both carbon and oxygen is opposite the direction of the vertical ion drift. The magnitude of the asymmetry generally decregaes towards the center of the discharge. A quanifluid necclassical model of impurity transport reproduces the observed aymmetries of $\mathrm{C} \mathrm{V}$ if the main 10ns are assumed to lie ir the banana regime. A simplified kinetic formulation of the problem leadi to anymmetries of approximately the correct magnitude, ، 'ut does not reproduce the observed scaling.

\section{ACKNOWLEDGMENTS}

Yie would like to thank Dr. R. Hulse for makiag his sne-dimensional transport code availabie, and Dr. R. Goldston for a critical reading of the manuscript. Some of the data discussed in this paper were provided by Dr. D. Johnson, Dr. B. Grek, Dr. G. Schmidt, and Dr. D. Manstield. We wish to thank the head of the PDX group, Dr, Kees Bol, and also the PDX operators and technical staff for their efforts in keeping the machine running smoothly. We acknowledge the engineering and technical support of D. Hay, H. Feng, R. Mika, R. Mullen, G. Drozd, and G. D'Amico for their work on the FARM. This work

supported by U. S. Department of Energy Contract No. DE-AC02-76-CHO-3073. 


\section{APPENDIX}

Here we derive the expression for the quasiluid model of impurity asymmetries. The impurity flow in a toroidally confined plasma may be described by the particle continuity and momentum equations:

$$
\begin{gathered}
\nabla \cdot n_{I} \mathbf{u}_{I}=S_{I} \\
-\nabla p_{I}-Z_{I} n_{I} e \nabla \phi+Z_{I} n_{I} \frac{\mathbf{u}_{I} \times \mathbf{B}}{c}+\mathbf{R}_{I I}=0 .
\end{gathered}
$$

where $u_{f}$ is the first order impurity flow velocity, $S_{I}$ represents atomic rates, $p_{I}=n_{I} T_{i}(r)$, taking the impurity and proton temperatures to be equal and constant on a flux surface, $Z_{I}$ is the ion charge, and $\mathbf{R}_{\| I}$ the friction force between inpurities and protons. The magnetic feld is assumed to be of the form

$$
\mathbf{B}=\frac{B_{0}}{h}(\hat{\theta}+\theta(\boldsymbol{r}) \hat{\varphi})
$$

with $h=1+6 \cos \theta$. In general, there are $\mathrm{N}$ coupled equations of this type for an impurity with nuclear charge $Z_{N}$.

The friction force $\mathbf{R}_{\boldsymbol{J}}$ is caleulated from

$$
\mathbf{R}_{\| I}=\int d^{3} \mathbf{v} m_{i} v_{\eta} C_{I i}\left(f_{I}, f_{i}\right)
$$

where $C_{J i}$ is the linearized Fokker-Planck collision operator for impurity-proton collisions, and $f_{Y}$ and $f_{i}$ the impurity and proton distribution functions, respectively. By expressing $C_{h i}$ in terms of the Rosenbluth po' intials and expanding in powers of $m_{i} / m_{I}$, in the limit of large impurity mass it can be shown that 
$\mathbf{R}_{\mid r}$ depends only on the two moments $n_{l}$ and $u_{\|}$of $f_{l}$. Straightforward computation yields

$$
\mathbf{R}_{\| I}=\frac{m_{i} n_{i}}{r_{i}}\left(u_{\|_{i}}-u_{\| I}+u_{\eta_{i}}\right)
$$

where

$$
\begin{gathered}
u_{\| i}=\int d^{3} v \frac{v_{i 1}}{n_{i 0}} \\
u_{\| I}=\frac{1}{n_{I}} \int d^{3} v v_{\|} f_{I} \\
u_{\| i}=\int d^{3} v\left[\frac{3 \sqrt{\pi}}{1}\left(\frac{v_{t i}}{v}\right)^{3}-1\right] v_{\|} \frac{f_{i 1}}{n_{i 0}} \\
v_{t i}=\sqrt{\frac{2 T_{i}}{m_{i}}} \\
r_{i j}=\frac{3 \sqrt{m_{i}} T_{i}^{3 / 2}}{\left.4 \sqrt{2 \pi} n_{I} Z\right\} \ln \Lambda} .
\end{gathered}
$$

In the small aspect ratio limit ( $€ \ll 1$ ) we have

$$
u_{\| i}=-\frac{e T_{i}}{e B_{0}}\left(\frac{n^{\prime}}{n}+\frac{e \Phi^{\prime}}{T}+1+g \frac{T^{\prime}}{T}\right)-\frac{e T}{e B_{0}}\left(\frac{n^{\prime}}{n}+\frac{e \Phi^{\prime}}{T}+T-g \frac{T^{\prime}}{T}\right) \epsilon \cos \theta
$$

and $g=1.7,0.5,-1.17$, respectively in the collisional, plateau, and $c_{v}$ ilisionless regimes. ${ }^{14,15}$ To calculate $u_{\|}{ }^{\prime}$ we employ previously derived expressions for the first order proton distribution function. ${ }^{10-18}$ Integrating $f_{i l}$ aver velocity, the terms which are proportional to a shitted Maxwellian vanish, and we are left with

$$
\begin{aligned}
u_{\|_{i}^{\prime}}^{\prime}= & 2 \xi \frac{\epsilon \epsilon T_{i}^{\prime}}{e B_{q}} \cos \theta \\
& -23-
\end{aligned}
$$



and

$$
A= \begin{cases}\frac{1.3}{v_{\mathrm{r}} r_{i i}} & \text { in the Phrach-Schlüter regime } \\ \frac{\sqrt{\pi}}{2} & \text { in the plateau regions } \\ 1.28 v, & \text { in the banans regime }\end{cases}
$$

where $\nu_{T}=v_{i} / R_{Q}$ is the ion transit frequency, and $\phi_{1}$ the first osder poloidally varying part of the electroatatic potential. The first term on the left hand side of Eq. (10) describes the diffusire spreadiag of impuritien driven by parallel pressure gradients; the term involving derivatives of $\chi$ deacribes the repulsion of the impurities from regions of high electrontatic potential, an effect which tends to reduce the anymmetry. In the origiral model by Burrell and Wong ${ }^{b}$ the diffusive spreading term was balanced by the fith term, which describes the effects of friction and thermal forces. Note that if the coefficient within the square brackets is negative, in other worde, if friction forces predorainate over thermal forces, or if the electrostatic potential term is sufficiertly large, the asymmetry is opposite the vertical drift. On the other hand, if the coeflicient within the square bracksts is positive, (true for $L_{T} / L_{n}<1-\xi-1 / Z_{\jmath}$ ) and the electrostatic term is small, the asymmetry is in the same direction as vקB. 


\section{REFERERCES}

[1] TERRY, J. L., MARMAR, E. S., GHeN, K.I., MOOS, W. H., Phys. Rev. Lett., 89, (1977) 1615.

[2] SUCKEWER, S., HINNOV, E,, SCHIVELL, J., Rapid Scanning of Spatial Distribution of Spectra Line Intensities in PLT Tokamak, PPPL1430.

[3] ALLEN, S., MOOS, W. H., RICHARDS, R. K., TERRY, J. L., MARMAR, E. S., Nucl. Fusion 21, (1981) 251.

[4] HOGAN, J. T., XIl International Conference on the Physics of Electronic and Atomic Collisions, Proceedings, Gatlinburg, Tena., (1981) 709.

[5] BURRELL, K. H., WONG, S, K, Nucl. Fusion 19, (1979) 1571.

[B] HUGheS, M. H., POST, D. E., J. Comp. Phys. 98, (1978) 43.

[7] HULSE, R., Numerical Studies of Impurities in Fusion Plasmas, PPPL1817, (1882).

[8] BOTTCHER, C., HEIL, T. G., XII International Conference on the Physics of Electronic and Atomic Collisions, Abstracts, Vol. 2, Gatlinburg, Tenn., (1981) 676 .

[9] OLSON, R.E., SH]PSEY, E. J., BROWNE, J. L., J. Phys. B 11, (1978) 699.

[10] SHIPSEY, E. J., BROWNE, J. L., OLSON, R. L., J. Phys. B 14, (1981) 869. 
[11] BUTLER, S. E., Phys. Rer. A 20 , (1979) 2317.

[12] JeIl, T., DalgarNo, A., J. Phy. B Lett. 12, (1979) 1557.

[13] PHANeUf, R., X11 International Conference on tho Physics of Electronic and Atomic Colliaions, Abutracts, Vol. 2, Gatlinburg, Tenn., (1981) 088.

[14] HazeltiNe, R. D., Phys. Fluids, 17, (1974) 961.

[15] HIRShMAN, S., SIGMAR, D. J., Nucl. Punion, 81, (1981) 1079.

[18] Hazeltine, R. D., HINTON, F. L., Phy. Pluids, 16, (1973) 1883.

[17] WONG, S. K., BURRELL, K. H., Phys. Fluids, 25, (1982) 1883.

[18] ROSENBLUTH, M. N., AUTHERFORD, P. H., TAYLOR, J. B., FRIEMAN, E. A., KOVRIZhNIKH, L. M., (1971), in Plasma Physics and Controlled Nuclear Fusion Research (proc. th lnt. Conf. Madison, 1971) Vol. 1, IAEA, Vienna (1971) 495. 


\section{FIGURE CAPTIONS}

FIG. 1. PDX Fast Rotating Mirror (FARM) diegnostic.

FIG. 2. Cross section of magnetic field geometry in standard PDX circular (rail limited) discharge.

FIG. 8. Nonsymmetric radial scan of C III.

FIG. 4. Ghordal profiles of $C$ Ill and $G$ V for $R_{\text {maj }}=143 \mathrm{~cm}$ (solid curves) and $R_{m a j}=152 \mathrm{~cm}$ (dashed curves) circular discharges.

FIG. 5. Time evolution of $n_{e} l$ (upper figures) and radial scans of $C$ III (lower figures) for two PDX circular discharges. During density fattening as a dmetry of C III roverses direction.

FIG. 0. Chordal profles of $\mathrm{O}$ III, C III, O V, and C V.

FIG. 7. (Left) Radial scans of C III during inner wall discharges for opposite directions of the vertical ion dritt. (Right) Schematic of C Ill distribution in inner wall discharge illustrating positions of intensity maxima.

FIG. 8. Radial scans of C Ill and C V in circuiar discharges. The dashed (solid) curve corresponds to a vertical ion drilt directed upward (downward).

FIG. 9. Experimentally observed values of $\eta$ for $\mathrm{C} \mathrm{V}$ plotted versus different quantities. (a) Quasi-neoclassical fluid theory scaling, main ions assumed to be in plateau regime: $L_{T}=10 \mathrm{~cm}, L_{n}=12 \mathrm{~cm},(b)$ same as above, but main ions in banana regime.

FIG. 10. Experimentally observed ralues of $\eta$ for $\mathbf{C ~ V ~ p l o t t e d ~ v e r s u s ~ d i f f e r e n t ~}$ quantities. (a) $\eta_{e x p}$ versus $\bar{\pi}_{*}$. (b) $\eta_{e x,}$ versus $\eta_{k i n}$.

FIG. 11. Density, temperature, and q profiles of discharges used in numerical modeling.

FIG. 12. Asymmetry parameter $\eta$ of $\mathrm{C}^{+1}-\mathrm{C}^{+5}$ (triangles) v8. minor radius from numerical modeling using 2-D transport code. In Figs. (b) through (d) $\nu_{i i}$ has been increasec by factors of 3,10 , and 100 , respectively, and 


$$
D_{A}=10^{4} \mathrm{~cm}^{2} / \mathrm{sec}_{,} v_{A}=-10^{3}(\mathrm{r} / \mathrm{o}) \mathrm{cm} / \mathrm{sec} \text {. }
$$

FIG. 12. Plot of $\eta$ for $\mathrm{C}^{+1}-\mathrm{C}^{+5}$ versue midor radius in 2-D modeling of charge exchange recombination thaory of poloidal aymmetries. In (b), (c), and $(d) n_{0}(r)$ has been increased by factors of 2,5 , and 10, respectively. 

* 82 POI24

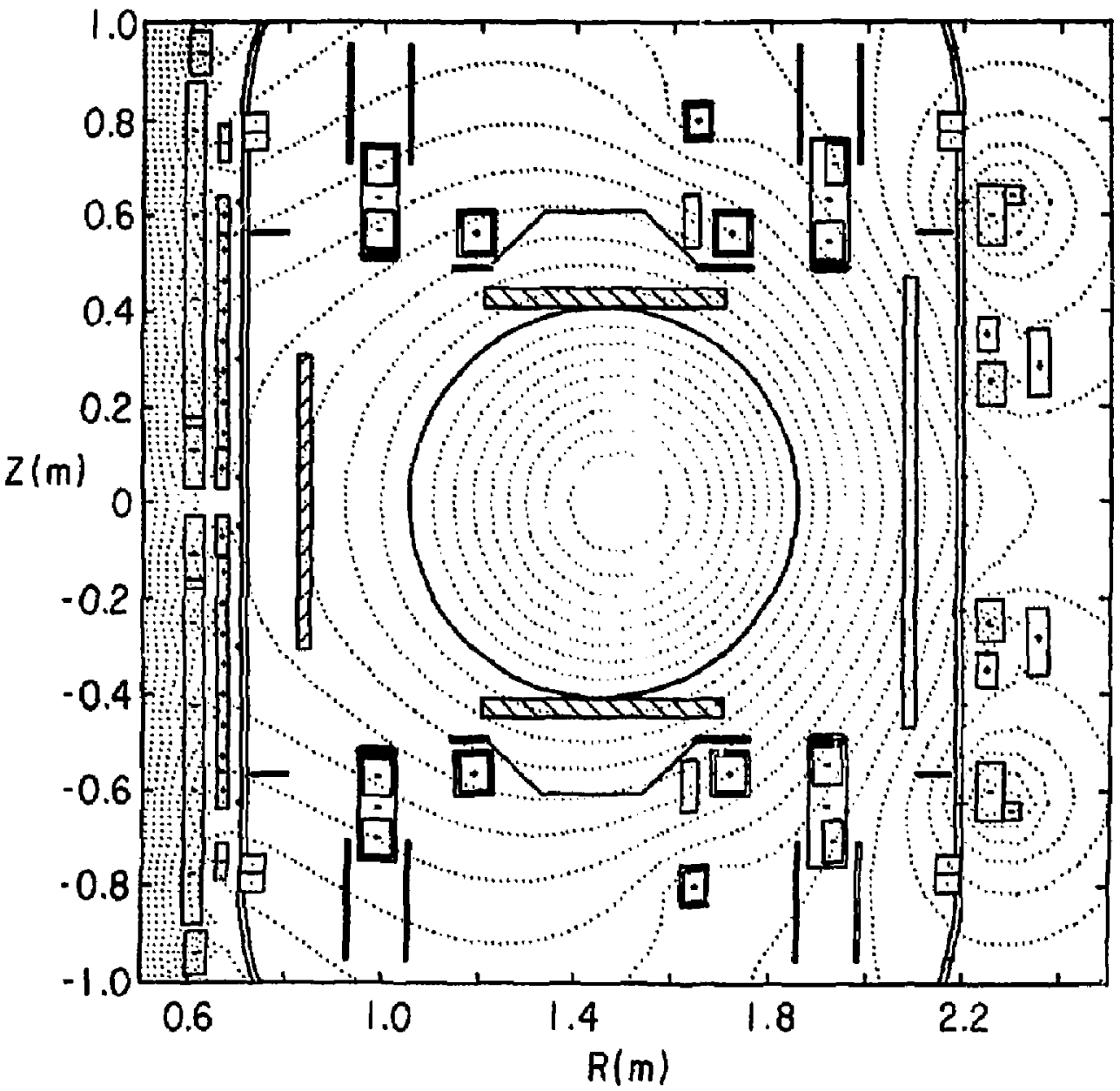

Fig. 2 


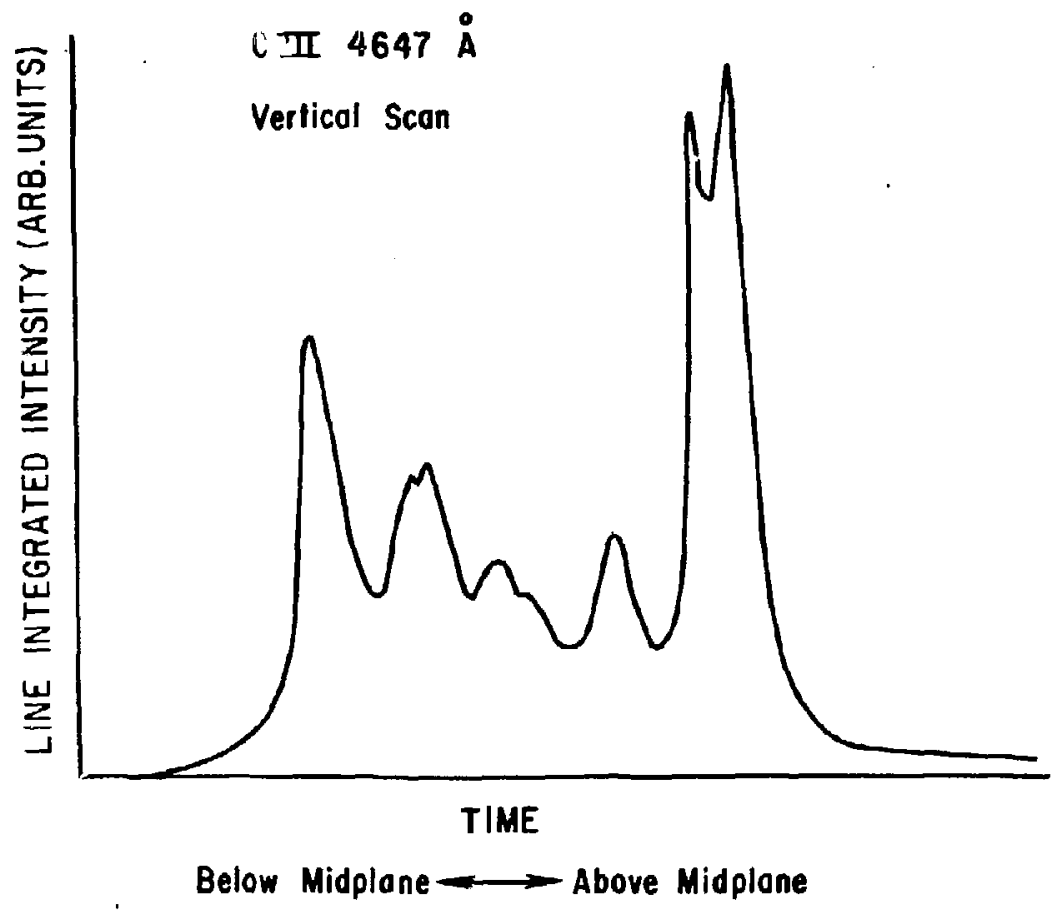

Fig. 3 

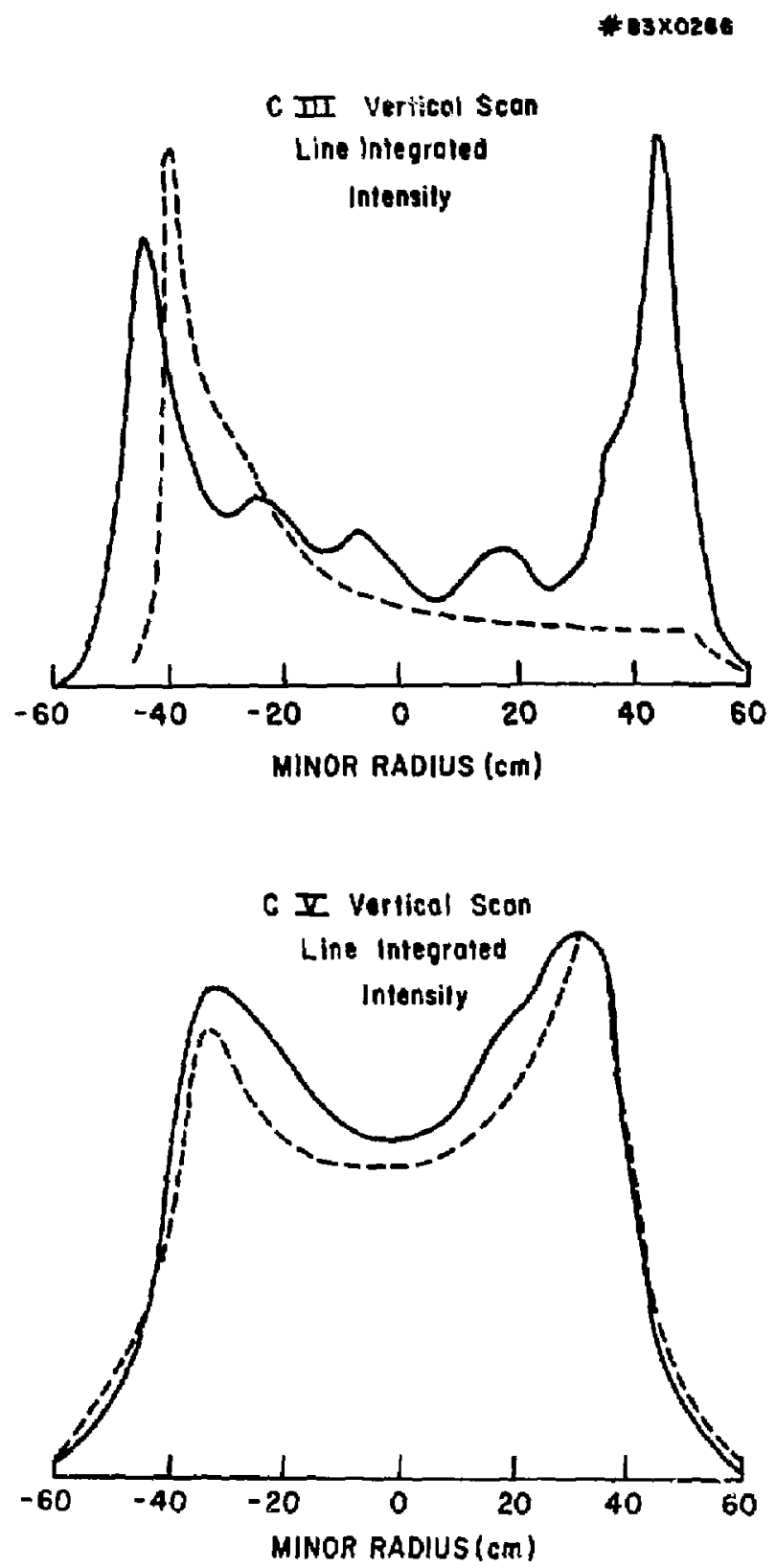

Fig. 4 

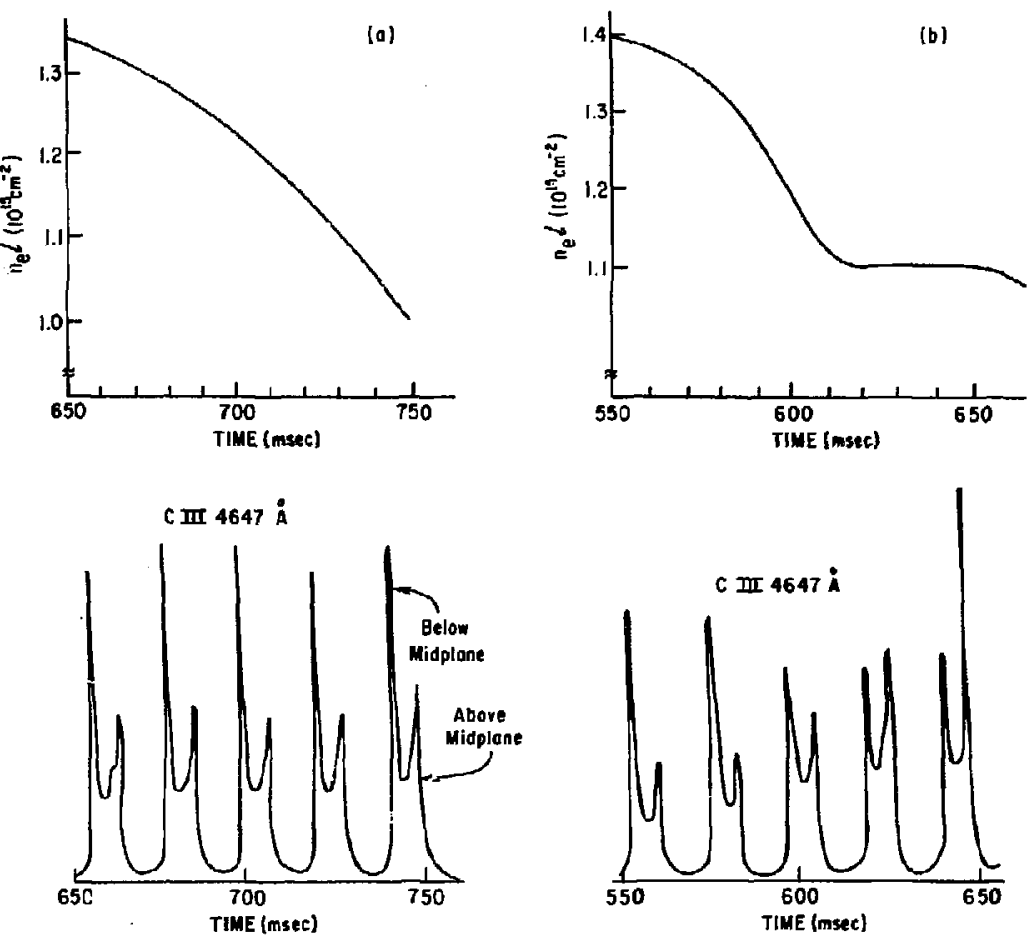

Fig. 5 

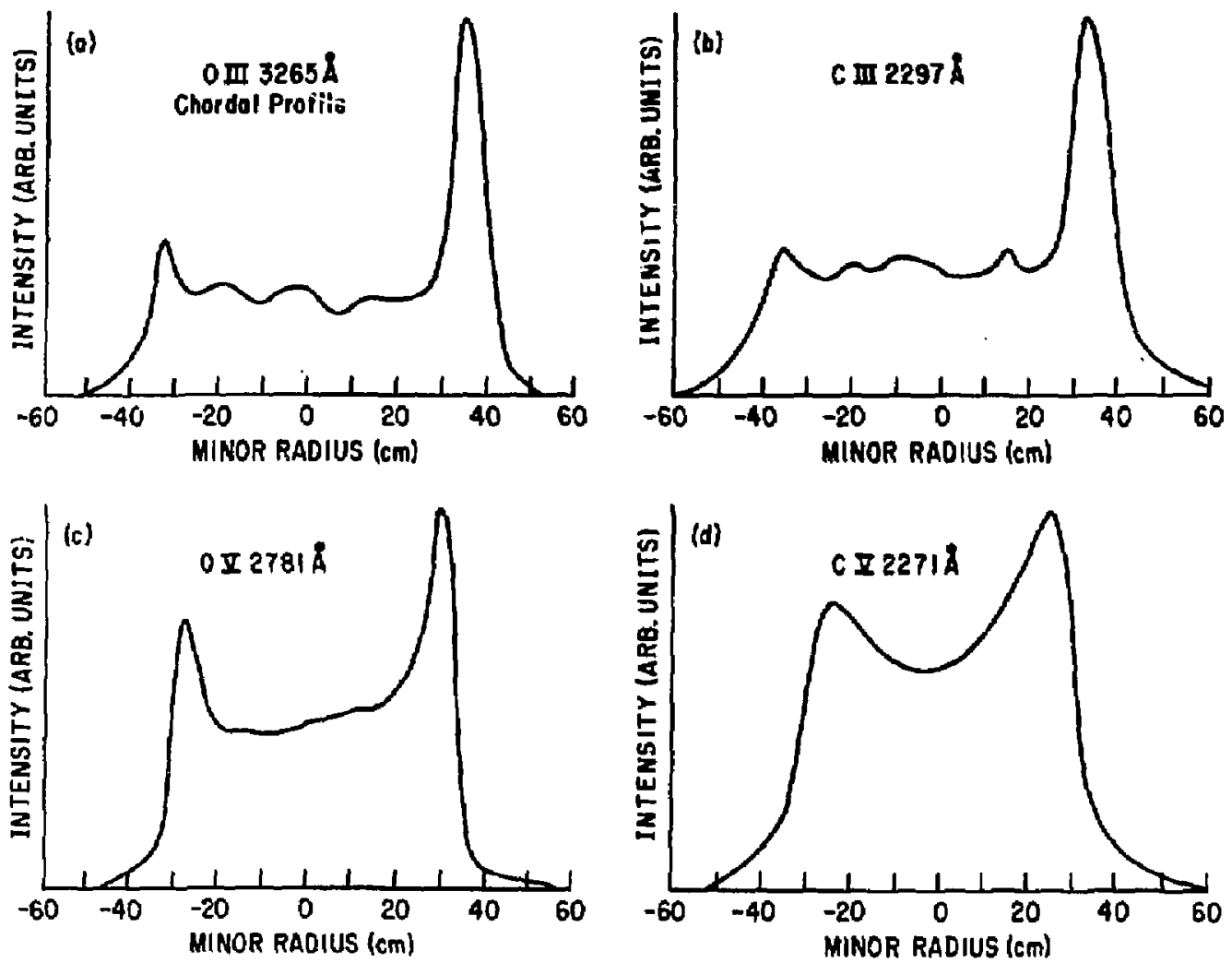

Fig. 6 

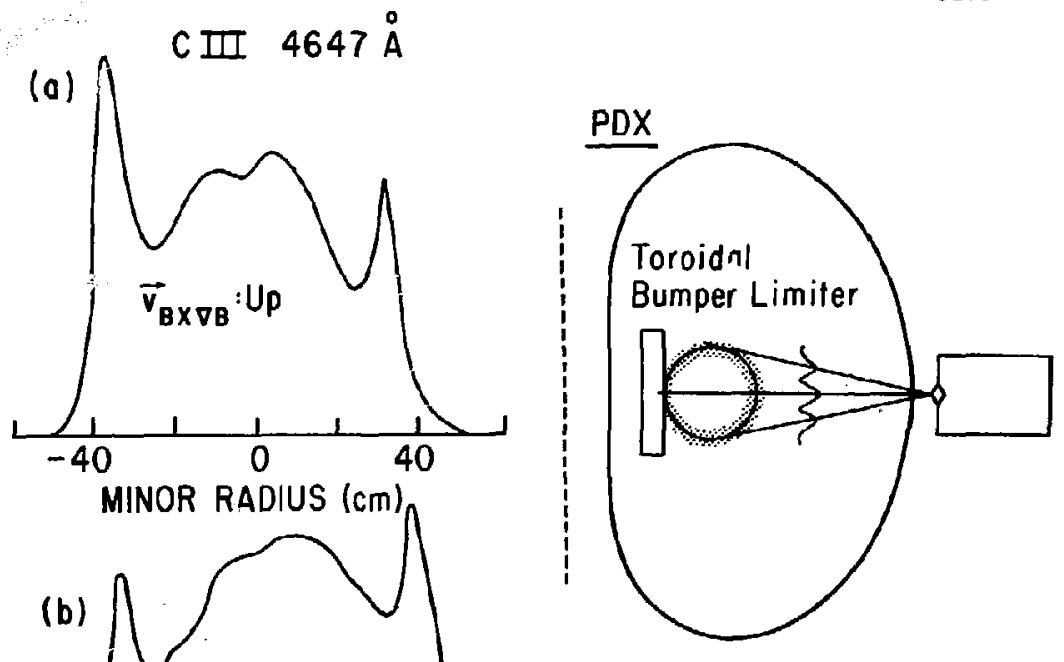

fig. 7 


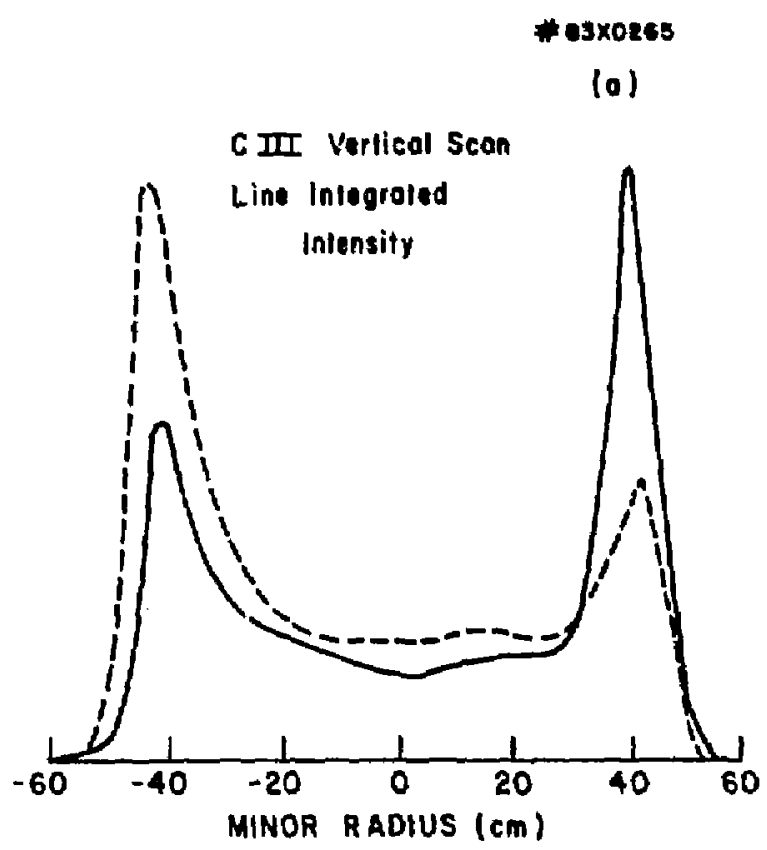

(b)

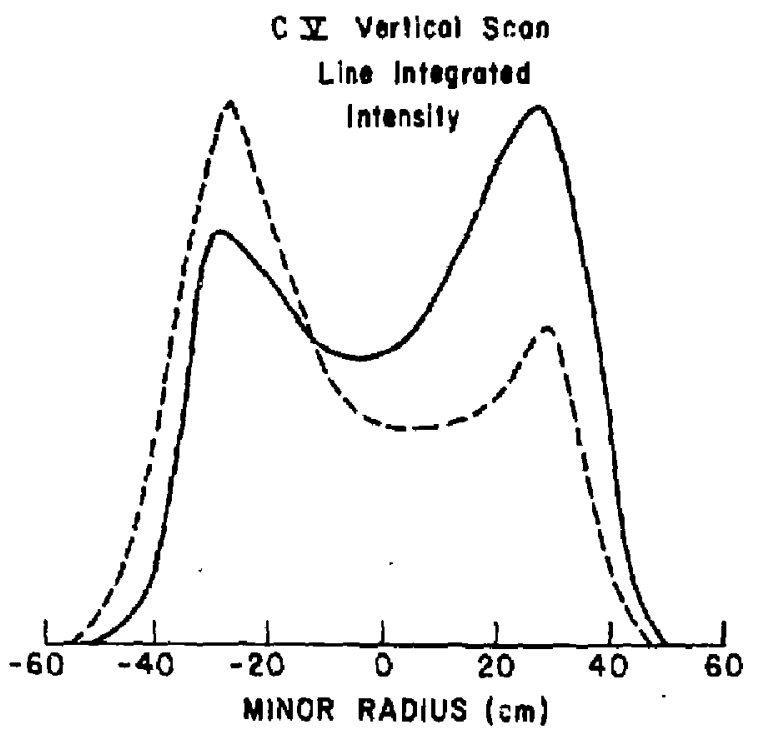

Fig. 8 

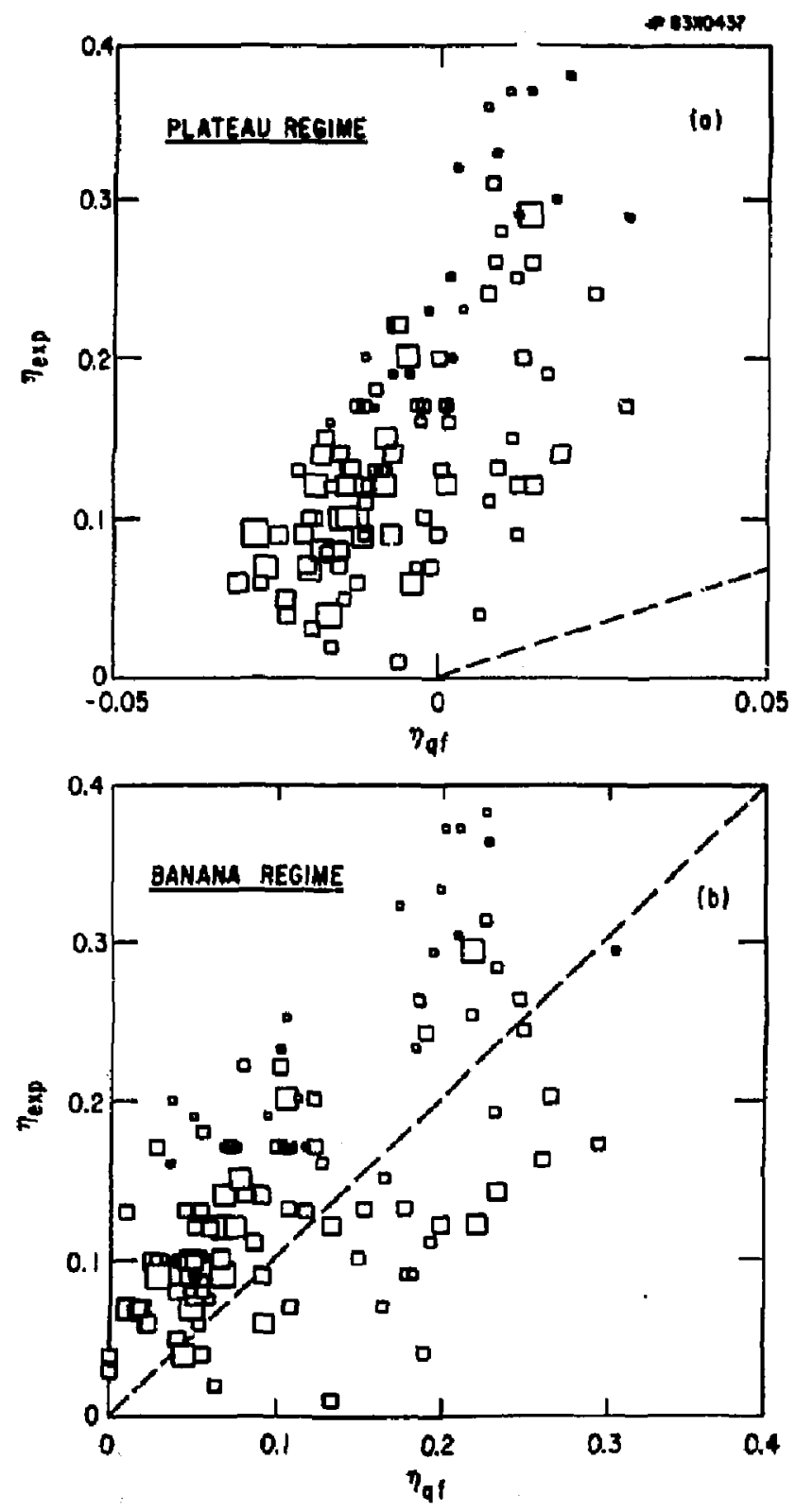

Fig. 9 

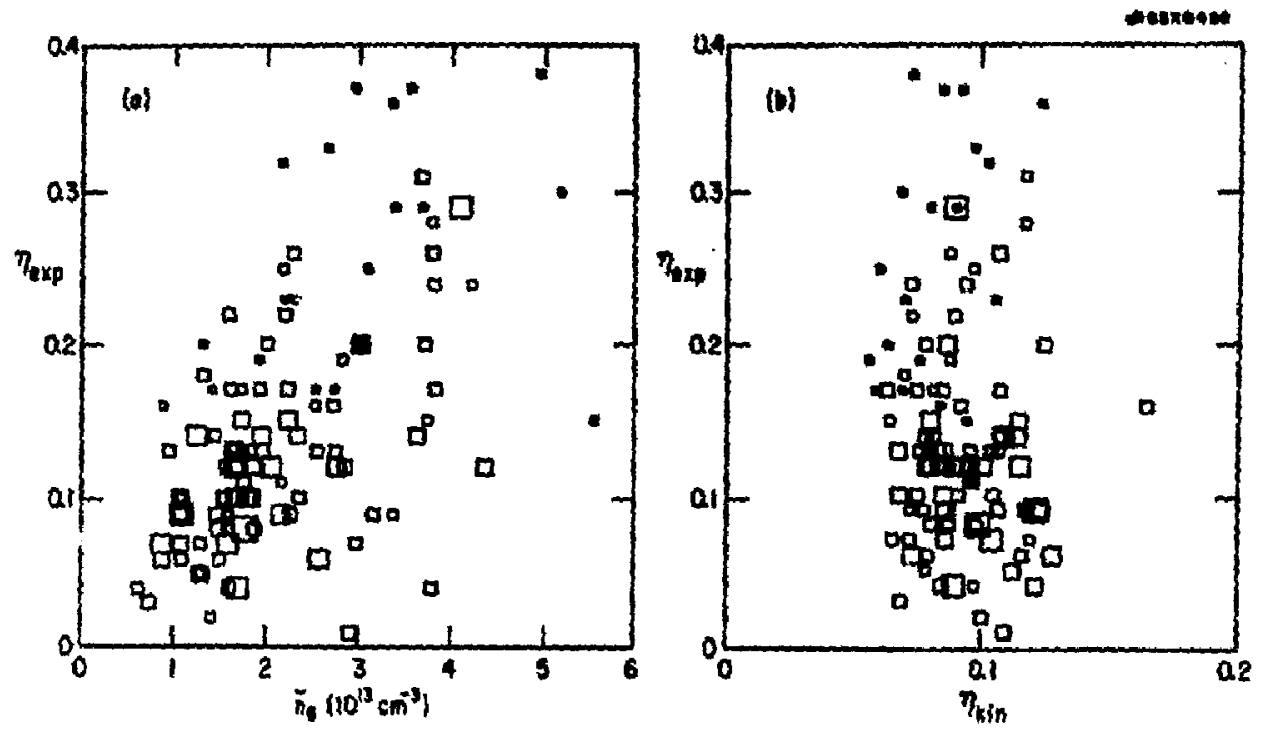

Fig. 10 


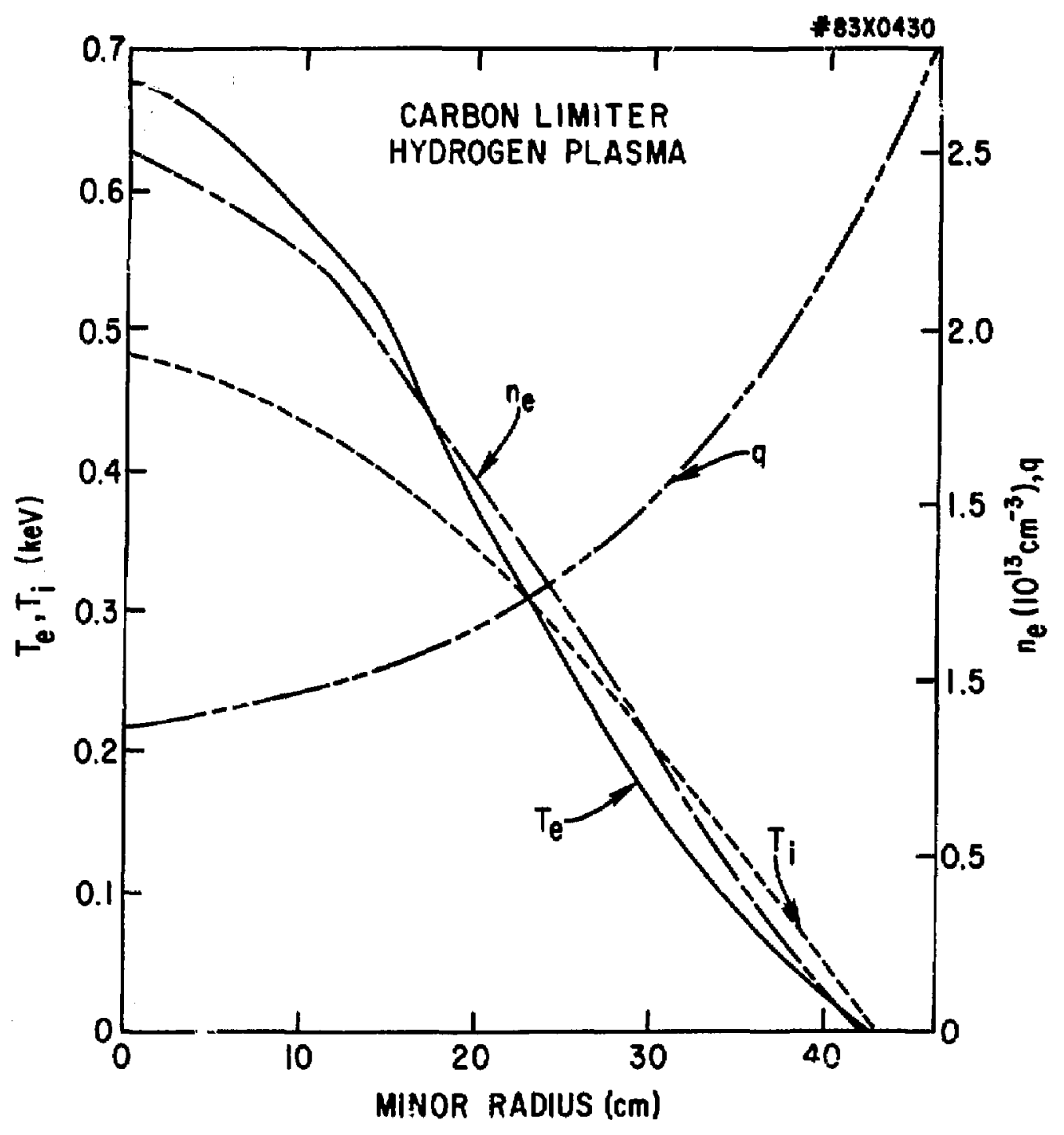

Fig. 11 

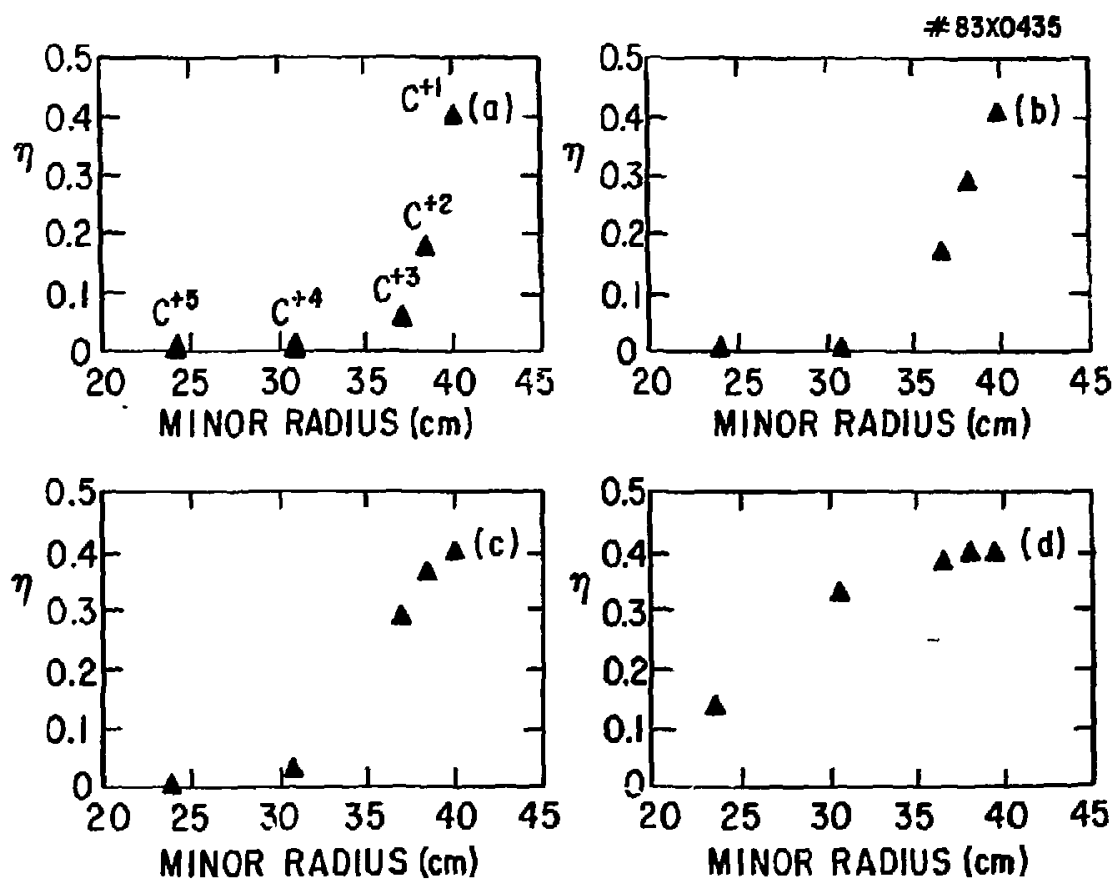
\# 83X0436
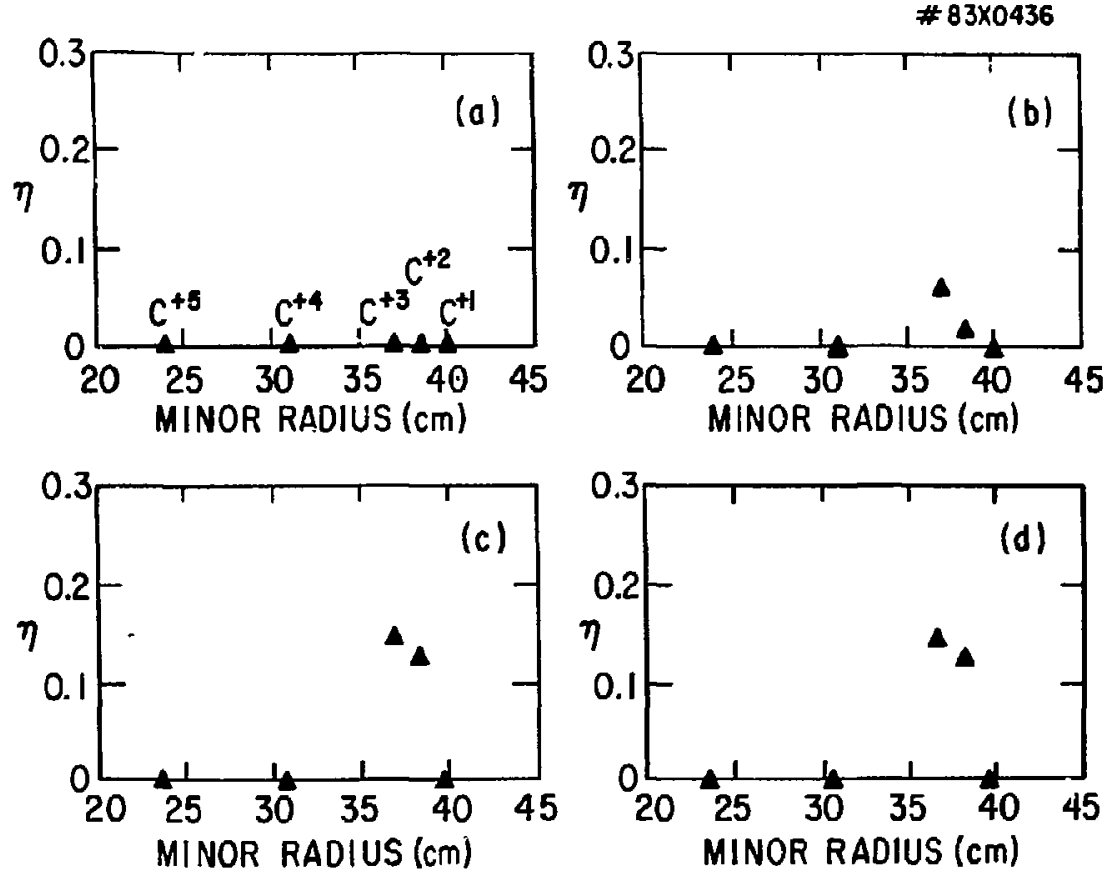


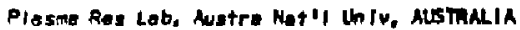

Dr. Fronk J. Peotonl. Univ of Wollongomg, AUSTRula

Prot, 1, $R$, Jones, Flinders Unlve, AUSThalia

Prot. WH. Brannen, UnIr Sydnc, Ausmal ia

Prot, f. Cod, Inst Theo Phys, AusteIA

Prof. Frent Yorheest, Inet theoretisehe, BELGIUM

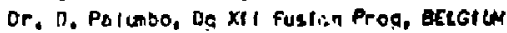

Eeole Royule millitalre, Lab do Phys Plasmas, oelgius

Dr. P.H. Sakgneke, Univ Estacuel, ERazll

Dr. C.R. Jemes, Unly of AlBerta, CAHAD

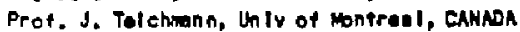

Or. H.H. Skarsoard, Univ of Saskatcheran, CAwOA

Prof. S.R. Sremivasan, UnIveralty of Calgary, CANAOA

Prof. Tudor $W$, Johnston, I MRs-Enerate, Carkod

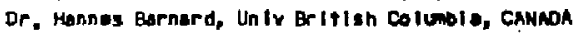

Dr. M.P. Bachinsk1, MPG Technologies, Inc., CAMHDA

Znengu LI, SH thet Phylics, CHIM

Llorary, Tsing Hua UnIversity, CHIM

Librarlan, Institute of Physirs, CHIMA

Inst Plasm Phys, sw Intt Phystas, CHim

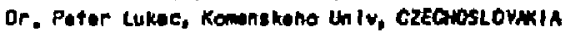

The Llbrarlan, Culham Laboratory. Ewalut

Prof. Schatzren, Observatolre a Mlce, FRakce

J. Redot, GEHED, FRnNeE

AM Dupes Library, AM Dupas Librery, FRMKEE

Dr. Tom Mual, Acedem Blbllographle, HOWG koho

Praprint Llbrary, Cont Ras Inst Phye, Muwgary

Dr. A.K. Sunderth, Phystcal Reseerch Lab, INDIA

Dr. S,K, Tranan, Panjab Un Ivorslty, IMOIR

Dr. Indra, Mohon Lal Cas, Banaras HIndu Unly, Fwots

Dr. L.K. Chavde, South GuJarat UnIY, IMDIA

- Dr. R.K. Chhajlonl. Var Ruchl Mara, Inola

P. Kaw, Physlcol Resuarch Lab, INDIA

Or. Phillip Rosenau, Isrool Inst Tech, I SRAEL

Prot. S. Oupormon, Tel Avly Un lversity, ISAaEL

Prot. 6. Rostaghi. Unir di Padon, ITAl

Librarlan, Int'l Ctr Theo Phys. ITALY

MI ss CIalia De Folo, As soe ELARTOA-CNEN, ITALY

Elblloteca, del CNR ELRATOM, ITALY

Dr. H, Yamato, Toshlba Res 3 Dor, JAPAH

Prot. M. Yoshlkaks, MERI, Tokn I Ras ESt, JAPAN

Prof. T. Uehlda, UnIversity of Tokyo, JAPAN

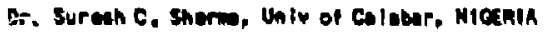
Prot.. JuA,C. Cabral, Inst suberlor Tech, POATuCaL

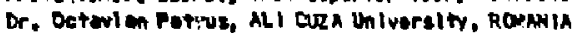

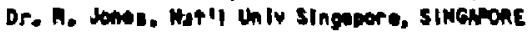
Prot, M, . He I lberg, Un Iverelty of Matel, SO AFRICA Dr. Johen de villlers, Atomle Energer Dd, 50 AFR ICh Or. J.A. Tagle, JEN, SPAIH

Prof, Kans wlimelmen, Chalmars Unir Tach, Sucoken Dr. Lonnart stentla, University of UMEA, SMEEH Llberary, Royal inst toch, steokn Dr. Er IK T. Kar Ison, Uppacia Un fuersitot, SMEDEH

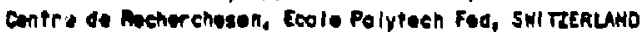
Or. W. We Ithe Nat'I Gur Stand, USA Dr, W,M, Steew, Georg Inst Tweh, USh Dr. S.T. Nu, Univ Alobem, USA Prot. Mormen L. Oleven, Un ir 5 florlde, USA Dr. Enjual in Mh, lowe stote Unir, USA Prot. Wopene Krlatlanien, Towe Tuch Un I.., USA Dr. Aermond Aakem, Auburn Un Iw, USA Or. V.T. Tol on, Kherlow thye Tech ins, ussR Dr. D,D, Ayutow, slberien Aeed Sel, ussh

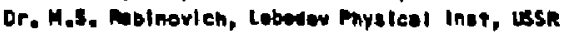
Dr. G.R. Ell- W, Kurchotow Inutitute, ussh

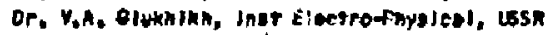
Prof. T.J. boyd, UnIv Colloge w wotes, wales Or. K, Schlindler, Puhr Unluersltat, W. Ceamayr Huelear the Estab, Julleh Lid, $W_{3}$ Gemiary Ll brarten, Maxtienck Intelltut, $W$, ceawaky Or. H,J, Kaopplor, Unlvarslty Stutgart, $W$, GefwaNy Bibllathek, Inst Ploumlorechung, W, GefwaNy 


\section{DISCLAIMER}

This report was prepared as an scoount of work sponsored by an arency of the United Stetes Governtrent. Neither the United States Gowemment nor any arency thereol, not any of their emptoyees, makes any warranty, exprese or implied, or aswumes any lesal lisbility or resposubility for the eceutuey, completenes, or uxefulness of eny information, epparatus, product, of process diactoesd, or represents that its use would not inftinge privately owaed rights. Refereace herein to any apecilic commercial product, proceses or sivice by Inde name, trademark, manufac. furer, or otherwise does nol necestarily coustitute or Imply its endorwement, recom. mendation, or favorine by the United States Covernment or any asency thereof, The views and opinions of authort expresed herein do not necestarly atste or reflect those of the United States Governinent os any arency thereof. 